\title{
ECOLOGICALLY ORIENTED AGRICULTURE IN UKRAINE: OPPORTUNITIES AND RISKS OF DEVELOPMENT
}

\begin{abstract}
O. Shubravska, K. Prokopenko*, L. Udova
Department of Forms and Methods of Economic Management in the Agro-food Complex, Institute for Economics and Forecasting, Ukrainian National Academy of Sciences, Kyiv, Ukraine

ABSTRACT

The structure of agriculture is increasingly corrected by the need to adapt production to increase the intensity of climate change that leads to building a new concept of resource-saving agriculture, determining the optimal sectoral structure of production and indicators for assessing the implication of adaptation technologies implementation. The aim of the study is to develop the concept of ecological resource-saving agriculture, which will ensure: preservation and reproduction of agricultural land fertility as a decisive factor in food security in the long term; improvement of food quality for the population; expansion of the export potential of agro-food products at the expense of the segment of high-quality, demanded and, therefore, competitive products. An assessment of the consequences of climate change for the industry and possible results of its adaptation suggests that the use of environmentally balanced agricultural systems will ensure adaptation of the industry to climate change on the basis of widespread introduction of innovative technologies that will promote the conservation and restoration of soil fertility, moisture conservation, reduction of production cost through minimization the cost of material resources. As the result, the sustainable productivity, profit increase and food safety while maintaining the resources and the environment will be achieved.
\end{abstract}

Key words: Agriculture, Climate Change, Environmental Restrictions.

\section{INTRODUCTION}

Agriculture plays an important role in the economy of Ukraine. This sector of the economy provides $12 \%$ of GDP, more than $40 \%$ of export revenues and domestic food security of the country. At the same time, it has significant growth potential and opportunities for solving global food security problems. However, neglecting environmental requirements for agricultural production for many years poses a threat to the loss of the country's agrarian potential. In particular, during the last years due to the influence of natural and anthropogenic factors deterioration of the quality of soil cover is observed on a considerable area of agricultural land. At

Correspondence to: Kateryna Prokopenko, Department of forms and methods of economic management in the agro-food complex, Institute for Economics and Forecasting, Ukrainian National Academy of Sciences, 01011, Panasa Myrnogo str., 26, Kyiv,Ukraine,E-mail: k_prokopenko@ukr.net, Phone: +380442889337 present, the area of eroded soils in Ukraine is 13.3 million hectares $(31.8 \%$ of agricultural land), 1.2 million hectares $(10.3 \%$ of agricultural land) of them are strongly ground soils. Its area is increased by 70-80 thousand hectares annually. The current situation requires the implementation of agroecological measures to stop and prevent future negative processes and preserve the natural resource potential of the agrarian sector.

At the same time, despite the fact that Ukraine is not yet among the most vulnerable to global climate change countries, the effects of such changes are becoming more pronounced on its territory. Therefore, the structure of agriculture should be adjusted taking into account the adaptation of production to the increase of the intensity of climate change. Adaptation to climate change requires almost all agricultural producers and other actors in the food chain to introduce new methods of management and make systematic changes to their strategies. 
In turn, agriculture is a significant source of greenhouse gas emissions, which is a key factor in global climate change. Therefore, increasing the volume of agrarian production may exacerbate the problem of increasing its negative impact on the environment, which requires the introduction of agricultural technologies aimed at reducing greenhouse gas emissions.

All of the above leads to the need to build a new concept of resource-saving agriculture, to determine the optimal sectoral structure of production and indicators for assessing the implications of adaptation technologies implementation.

The main objective of the study is to develop the concept of ecological resource-saving agriculture, which will ensure: preservation and reproduction of agricultural land fertility as a decisive factor in food security in the long run; improvement of food quality for the population; expansion of the export potential of agro-food products at the expense of the segment of high-quality, demanded and, therefore, competitive products.

\section{MATERIALS AND METHODS}

The authors used such methods for the solution of the tasks and achieving the goals as analysis and synthesis, the axiomatic method, the method of the statistical groupings and comparison, induction and deduction, a structural-functional approach. The study is based on a comparative analysis and synthesis of scientific literature.

The study was taken into account that for Ukraine the impact of climate change is still too threatening, but early warning of possible negative consequences of such influence is a key to increasing the sustainability of domestic agricultural production and the entire national socioeconomic system.

For the last 20 years, the average annual summer temperature in Ukraine has increased by $0.8^{\circ} \mathrm{C}$ compared to the climatic norm (1961-1990), and the average winter temperature has grown by almost $2^{\circ} \mathrm{C}$. This led to an increase in the frequency and force of extreme weather conditions (abnormal heat in 2006, 2008, 2010, 2012, 2014, 2015, record snowfalls in the west and central part of the country in March 2013, etc.) (1).

Significant increase in the maximum and, in particular, the minimum air temperature during the cold period of the year resulted in a decrease in the duration of the last (for 5-28 days) and stable snow cover, as well as the number of frosty days and the severity of winter. Therefore, in Ukraine there is a tendency to increase the duration of the warm period, which begins 15-20 days earlier in spring and ends1-6 days later in autumn. Early onset of the warm period causes early revival of plant growth, which is why such crops often fall victim to the effects of late spring frosts (1).

The increase in average annual temperatures has already led to a shift from the south to the north in a number of crops, in particular, sugar beet and soybeans. Warming is also associated with an increase in the number of pests in the fields, areas of eroded lands, landslides, etc.

According to the forecasts of the World Bank, the increase in air temperature in Ukraine until 2100 will increase the capacity of crop yields such as cereals, corn, sunflower, soybean, rice, wheat, melon, cotton, vegetables, walnuts, peaches, apricots, apple, cherry, plum, grapes (2). In particular, the expected increase in the process of photosynthesis by $30-100 \%$ can accelerate the growth and maturation of wheat, barley, sunflower and, respectively, increase their yield by $20-30 \%$. At the same time, increasing the content of carbon dioxide with a positive effect on crop yields will lead to deterioration of grain quality (2).

Thus, the following climate change in Ukraine will have a negative impact on agricultural production and can reduce it by $15-50 \%$ :

- increasing the repeatability and severity of droughts during the growing season;

- increasing the frequency of spontaneous hydrometeorological phenomena during the warm period of the year (heavy rains, thunderstorms, tornadoes, squalls, hail, etc.);

- changing the nature of precipitation during the growing season (decreasing the rate of fall and increasing the intensity), which prevents the effective accumulation of soil moisture and worsens the conditions for harvesting and quality of products;

- increasing the frequency and intensity of late spring frosts;

- absence of a stable snow cover (dry winter), which, due to the periodic significant decrease of temperature, increases the risk of freezing the winter crops.

In this context, an attempt was made to assess the effects of climate change on the industry and possible results of its adaptation. The 
authors developed the analytical model. The main factors of influence (i.e. constraints/incentives) are agroinnovations, climate change and environmental standards. The impact of climate change on agriculture is reflected by fluctuations in the sectoral structure of production by main agricultural crops (wheat, corn, sunflower which form more than a half of the gross output of enterprises) and cattle as an important component of rational agriculture. The calculations were differentiated in terms of three time periods - the base (actual state of production according to 2017), medium and long-term (till 2027 and 2037 respectively), as well as the four main climatic zones of Ukraine (Polissya, Forest-steppe, Steppe and Prykarpattya). An indicative branch structure was formed for each of these zones in accordance with the worked out agroecological requirements.

The analysis of climate change impact on the prospects of domestic agricultural production development was carried out in two scenarios - basic / traditional and rational / innovative and in the context of the following assumptions:

Scenario S1. Agricultural production is carried out without implementing measures of rational agriculture, i.e. high results are achieved by predominantly industrial agro-innovations. Such type of management is characterized by intensive cultivation technologies, newest resources (GMOs, hybrids), wide use of chemical fertilizers and plant protection products, etc.

Approximate estimates of expected effects were based on the following assumptions:

- the demand for selected agricultural products (which are at the same time the most significant for the industry and its exports) has no restrictions;

- total sown area is unchanged. For S1, the structure of sown area in the medium and longterm does not fundamentally change, because the basic principle is the industrial highefficient agriculture;

- the estimation of crop yield change was carried out by spreading the trend provided that companies continue to introduce new industrial technologies and resources. In order to take into account the impact of climate on yields in the long run, the results of forecasting changes in the climate system from the Fifth Report on Climate Change Assessment were taken into consideration. Namely, depending on the adaptation scenarios, there is a significant probability for the period 20302049 to reduce the yield by more than $25 \%$ (for S1) compared to the end of the 20th century (6);

- for S1 the cattle population was determined according to the trend. It should be noted that if the current tendency preserved, in 20 yearstime the cattle will no longer exist in the zone of the Steppe.

Scenario S2. Agro-business is carried out with large-scale introduction of technologies of rational agriculture and implementation of measures on adaptation of agriculture to climate change.

According to FAO definition, rational agriculture technology is an environmentally effective and climatically optimized agricultural method to ensure sustainable productivity, profitability and food security while maintaining and strengthening the resource base and the environment. It is characterized by minimal soil damage during its mechanical treatment, organic fertilizers usage, diversification of agricultural production in accordance with crop rotation, contributes to reducing soil erosion, preserving their fertility and strengthening their resistance to drought, significantly reducing the cost of production by minimizing fuel consumption (3).

Approximate estimates of expected effects were based on the following assumptions:

- the demand for selected agricultural products (which are at the same time the most significant for the industry and its exports) has no restrictions;

- total sown area is unchanged. For S2, environmental constraints for the structure of sown areas should be in line with the recommendations of domestic scientists (4). They are also reflected in the resolution of the Cabinet of Ministers of Ukraine (5). In accordance with these requirements, an indicative structure was formed for each of four climatic zones;

- in order to take into account the impact of climate on yields in the long run, the results of forecasting changes in the climate system from the Fifth Report on Climate Change Assessment, were taken into consideration. Namely, depending on the adaptation scenarios, there is a significant probability for the period 2030-2049 to increase the yield by $10 \%$ (for S2) compared to the end of the 20th century (6); 
- for S2 the cattle population was determined according one of the main requirements of rational agriculture - preservation and, preferably, restoration of soil fertility. It should be noted that organic fertilizers cannot be replaced even by large doses of mineral fertilizers, although the latter can increase the yield of agricultural crops. According to calculations of experts, in order to achieve a positive balance of humus in soils of Polissya, its proportion should be not less than 18-20 t/ha, for Forest steppe - 13-15 t/ha, for Steppe $-10-12 \mathrm{t} / \mathrm{ha}$. To increase the humus content in the soil, it is also necessary to add perennial grasses in the crop rotation, which have not only a powerful root system, but also are easy to cultivate (7). Thus, in order to restore and preserve the soil fertility, it is necessary to change the structure of the livestock (to increase the share of cattle) and the crop area (to increase the share of forage crops, in particular perennial grasses and legumes). Calculating the required cattle population, it was assumed that it would provide half of the need for organic fertilizers; the remaining need would be provided by less quality organic matter from other species of livestock and poultry, by fodder and legumes.

\section{RESULTS AND DISCUSSION}

In all scenarios, there is an increase in wheat and corn production, but ignoring environmental conditions and climate change (S1) in the long term, production will start to decline, while in S2 - production will grow at a slower pace but steadily. The potential effect from the implementation of the presented scenarios is shown in Table $\mathbf{1}$.

Table 1. Production of some agricultural products by different scenarios, thsd. tonnes

\begin{tabular}{|l|c|c|c|c|c|}
\hline \multirow{2}{*}{$\begin{array}{c}\text { Crops / types } \\
\text { of animals }\end{array}$} & \multirow{2}{*}{$\begin{array}{c}\text { Base level } \\
\mathbf{2 0 1 7}\end{array}$} & $\begin{array}{c}\text { medium - } \\
\text { term } \\
\text { perspective }\end{array}$ & $\begin{array}{c}\text { long-term } \\
\text { perspective }\end{array}$ & $\begin{array}{c}\text { Scenarium - } \\
\text { term } \\
\text { perspective }\end{array}$ & $\begin{array}{c}\text { long-term } \\
\text { perspective }\end{array}$ \\
\hline Wheat & 20695.3 & 25260.9 & 21521 & 27636.7 & 30400.4 \\
\hline Corn & 20319.2 & 29220.1 & 22572.2 & 25729.2 & 28302.1 \\
\hline Sunflower & 10580.7 & 16581 & 14125.1 & 6796.7 & 7476.4 \\
\hline Milk & 2669.2 & 2799.5 & 2146.8 & 11160 & 27000 \\
\hline Beef & 93.7 & 70.7 & 40.7 & 434 & 1100 \\
\hline
\end{tabular}

Source: it is calculated by authors based on the data of State Statistics Service of Ukraine.

The analysis of the results showed the existence of certain risks for the agrarian sector for a very important sub-sector of sunflower cultivation and processing. This sub-sector now occupies an important place in the gross production and export of the country, significant capacity for processing sunflower seeds have been built up, where added value is created. However, the reduction in sown area of sunflower, which currently occupies more than a fourth of the area of agricultural production in agricultural enterprises, is inevitable if we want to preserve ecologically resource-saving agriculture and preserve the black earth in the future. One way to solve this problem may be to increase the productivity of this crop. At present, the potential yield of the best hybrids of sunflower, grown in compliance with all technological conditions, is $5 \mathrm{t} / \mathrm{ha}$. If domestic farmers can reach such a result in sunflower seed production with its optimal share in crop rotation, it can reach 10 million tons.

Another risk is the growth of milk and beef production. A significant increase in cattle population is needed to maintain soil fertility, but the issue of processing such volumes of production and finding directions of implementation will arise. By dividing the meat and dairy production and increasing the area under fodder lands is likely to reduce production costs and improve product quality, which will open the way for export, in particular to the growing Asian markets.

Concerning the risk of increasing environmental pollution due to increasing the number of cattle, it should be noted that in Ukraine such livestock has decreased to a level that is critical for food safety and soil fertility conservation. In 1990 Ukrainian agricultural land was more fertile and there was 0.5 head of cattle per 1 ha of agricultural land. At present, in the European Union, 1 hectare of agricultural land accounts for 0.5 head of cattle, in Ukraine - 0.08 head of cattle. According to our estimates, it is optimal to increase the cattle number to 0.3-0.4 head of cattle per 1 ha of agricultural land $(8,9)$. This will cause increase in environmental pollution, but insignificant, because emissions from 
intestinal fermentation of cattle are currently less than $1 \%$ of all emissions from pollution sources. However, the cattle population should be controlled and the growth of production must be attained primarily by increasing productivity (10).

The consequence of such changes will be the preservation of diversified rational agriculture in the long term.

Of course, one should be careful about the results of forecasting the volumes of agricultural production in conditions of climate change, if these forecasts do not take into account factors such as land degradation, access to better resources, farmers' readiness to change farming practices, etc. (11).

According to the forecasts of the World Bank, technologies of rational agriculture in the medium term may spread in Ukraine to an area of up to 9 million hectares in the Steppe area (where all land is suitable for this technology to be applied at). It is also expected that the technology will gradually spread to the Foreststeppe zone on about 17 million hectares in long term (12).

The problems of agriculture in Ukraine, due to the need to minimize the negative effects of climate change, are exacerbated by the insufficient overall resistance of the domestic agro-food system to ecological and economic challenges due to its low level of sustainability (in terms of the balance of economic, ecological and social components of the development of such a system). Consequently, the process of adaptation of the industry to climate change is inextricably linked to the provision of its sustainable development, which is being achieved around the world on the basis of the wide introduction of innovative technologies. It is estimated that every dollar invested in agrarian science and related developments has generated over 62 USD of national wealth in the countries of Europe, 46.5 USD in the USA and Canada, 37.4 USD in Japan and Israel, and almost 43 USD in Latin America (13).

Nowadays Ukrainian agrarians, although not everywhere, but quite widely use elements of innovative production technologies, primarily seed and breeding material, as well as more or less modern, especially domestic, agricultural machinery (as a rule, second-hand imports). More and more actively implemented moisture-saving No-till and Mini-till technologies, precision agriculture, and dynamically developing organic production. Domestic experts in the field of IT technologies note the growing interest of agricultural producers, especially crop products, in the use of innovations. To a certain extent, the economic crisis and the limited financial resources of the industry contributed to it. In such a situation it is quite logical to reduce as much as possible unproductive production costs and to increase predictability of the final result. The most widespread in the agrarian sector are innovative solutions: satellite monitoring of fields, weather stations, agrochemical analysis of soils, systems of monitoring the technology and fuel control, systems of field history management, as well as land bank management (14).

The important indicators of the innovation of the industry (as well as the country as a whole) are investments, including foreign, which characterize the potential of innovation development and reflect the quality of the national business environment and the state of the domestic market.

The level of capital investment in agricultural enterprises in Ukraine remains unsatisfactory. Thus, in 2016, investments in comparable prices in 1996 amounted to $43.0 \%$ of the level in 1990, and investments per hectare of agricultural land $-80.2 \%$.

At the same time, it should be noted that the investment activity of enterprises in 2016 has gradually restored in comparison to the crisis of 2014 (when the investment index was $84.6 \%$ ). The process of restoration of investment activity in agriculture continues, since in 2017 the index of investments amounted to $131.2 \%$ (while in the whole economy $-122.1 \%$ ).

Obviously, achieving further growth of the agrarian sector is possible only on the basis of effective and massive use of existing knowledge by agrarians, as well as investment in innovation to ensure sustainable productivity of agricultural plants and animals. The set of appropriate measures is not universal, but should be formed taking into account the climatic and other peculiarities of particular regions in respect of the principle of priority in relation to the identification and distribution of the most resource-efficient and environmentally-friendly agricultural practices. 
Among the most widespread measures used by agricultural producers are: organic farming, growing the most "environmentally friendly" varieties or types of agricultural crops; increasing diversification of varieties and crops and using integrated agro-systems; improving water conservation technologies; implementing conservation measures for water resources, improving drainage systems on farms, introducing alternative moisture-saving agricultural practices, using manure, compost, cover crops to improve water retention; optimizing diets of animals, reducing-the concentration of livestock; regulating potential pests and diseases, etc. Organic agriculture promotes the development of social sphere of the countryside (through the growth of agricultural employment) along with the undeniable benefits to the environment. In this context, it is important to implement in Ukraine key provisions of the European organic legislation and the best European practices of organic production.

According to the areas of certified organic land, Ukraine is currently 11th in Europe. In 2016, it was estimated at more than 400 thousand hectares, which, however, is less than $1 \%$ of the total agricultural land of the state (15). The number of operators of the organic market at the beginning of 2017 amounted to 426, including 294 agrarian enterprises specializing in the cultivation of both traditional grain crops and niche crops, in particular, berries (16). For example, the agricultural group "Arnika", which operates in the Poltava region, grows certified organic products on an area of 6.3 thousand hectares. In addition, more than 9.5 thousand hectares of land which belongs to this company, have a transitional status. Produced products (mainly cereal and oil crops) are supplied to a number of EU countries, as well as New Zealand and Australia. The group of companies "Riter Bio Agro", which uses 3.5 thousand hectares of organic land in the Rivne region, grows strawberries and raspberries in addition to cereals and oilseeds. Its products are exported to Europe (15).

According to the Federation of Organic Movement, the domestic organic products market in Ukraine during 2005-2017 grew 147 times: from 200 thousand euros to 29.4 million euros. However, given the generally low purchasing power of the population, the potential for its growth is not currently significant enough. Therefore, the prospects for the development of domestic organic production are mainly related to exports, first of all, to the EU: sunflower seeds, soybeans and cereals; high protein crops for feeding animals; processed fruit and berries as ingredients of finished products; walnuts; medicinal herbs, aromatic plants, honey (17).

The main factors behind the deterrence of the widespread use of organic farming in Ukraine are the following: improper legal regulation; lack of state financial support; low domestic solvent demand; inadequate to the needs of the organic sector infrastructure development.

A comparative assessment of the Ukrainian (18) and European (19) legal and regulatory framework in the sphere of regulation of the organic sector allows us to ascertain the convergence of the contents of the indicated documentation as a whole. The Association Agreement between Ukraine and the EU also aims at this, Article 404 of which stipulates that "the promotion of modern and sustainable agricultural production, ..., in particular the expansion of the use of organic production methods and the use of biotechnology ..." (20). In order to accelerate the development of the domestic organic sector at the state level, first of all, it is necessary to focus on the practical implementation of the declared strategy of priority development of organic production in Ukraine, which requires:

- to form proper regulatory and effective national certification system;

- to provide targeted financial support to producers, in particular, during the period of their conversion to organic farming;

- to stimulate research and development in the field of organic production, to provide informational, consulting, educational services to operators of the organic sector (including supporting their communication with domestic consumers), to promote domestic organic products on the Ukrainian and international markets;

- to develop the infrastructure of the organic market, in particular, on the basis of stateprivate partnership;

- to support co-operative movement in the organic sector and production of processing / primary processing of products of organic cooperatives;

- organize the collection and processing of information on operators of the organic sector in the context of the relevant indicators of Eurostat. 
At the macro level, support for agricultural producers should focus primarily on ensuring the implementation of evaluations and providing information to agricultural government agencies on the possibilities of implementing resource-efficient practices, including using special budget financing programs; modernization of knowledge dissemination and best practice services; dissemination among farmers information on existing genetic resources and their wild relatives, as well as species that can be used in the future and improving access to them (both physical and legal through the purchase of copyrights); increase the possibilities for farmers to self-finance the abovementioned activities, as well as food processing enterprises to increase their own revenues; assistance in the development of agri-insurance systems (by partially subsidizing farmers' costs) to hedge the uncertainty associated with weather risks; improvement of land use based on the use of a landscape approach, etc.

The ability of the industry to adapt is determined not only by the availability of investments but also by the willingness of producers to take the necessary measures.

Indicators of successful implementation of the measures can be:

- stabilization and growth of humus;

- decrease of volatility of productivity of all types of cultivated crops.

\section{CONCLUSION}

Further growth of agrarian sector on the basis of sustainability is possible only on the basis of effective and massive use of existing knowledge by agrarians, as well as investment in innovation to ensure sustainable productivity of agricultural plants and animals. The results obtained by the authors allow stating the following points:

- growth of wheat and corn production is expected for the medium term (next 10 years) according to both scenarios;

- aforementioned crops production will gradually decline for the long term (next 20 years) under conditions of ignoring the environmental constraints and climate change, and following the innovative scenario - will grow steadily, but lower than now;

- there is every reason to expect significant risks of further development of sunflower production and processing. According to traditional scenario, farmers can expect production growth only in the medium term, but in the long term the output will fall due to lower productivity of this culture;

- Ukrainian farmers can reduce the cost of beef production and enhance the quality of products under conditions of providing the separation of meat and dairy cattle breeding and increasing the forage lands, that will provide domestic demand and expand export availabilities.

In this context, taking into account European experience, the first priority for Ukrainian agrarians is to promote the widest use of soil and moisture conservation practices by producers (in particular, Mini-till and No-till), expansion of cover areas and use of drought resistant agricultural crops, development of economical irrigation systems, optimization of diets in feeding animals and proper use of their waste in crop production. At the governmental level, it is necessary to focus first on the assessment of the vulnerability of natural resources (especially in the Steppe zone) and the readiness of farmers to adapt to climate change, dissemination of information among farmers to the best world-wide experience of climate adaptation, assistance to small and medium-sized producers in expanding funding sources for adaptation measures practice, the establishment of an effective system of subsidized agro-insurance, in particular, on weather risks.

An assessment of the consequences of climate change for the industry and possible results of its adaptation suggests that the use of environmentally balanced agricultural systems will ensure adaptation of the industry to climate change on the basis of widespread introduction of innovative technologies that will promote the conservation and restoration of soil fertility, moisture conservation, reduction of production cost through minimization the cost of material resources, the result of which will be the achievement of sustainable productivity, profit increase and food safety while maintaining and strengthening the resource base and the environment. If environmental norms and opportunities of innovative resource-saving approaches to agricultural production are neglected there is a high risk in the loss of domestic resource potential and reduction of productivity and efficiency of agrarian production the long-term.

\section{REFERENCES}

1. Kul'bida, M., Barabash, M., etc. Climate in Ukraine: in the past...and to the future? Kyiv, pp. 85-98, 2009. 
2. The World Bank Group. Climate Change Knowledge Portal. Available online: http://www.sdwebx.worldbank.org/climatep ortal/index.cfm?page=country_impacts_agr iculture $\&$ ThisRegion $=$ Africa $\&$ This Ccode $=$ UKR

3. FAO., Conservation Agriculture. Available online: http://www.fao.org/ag/ca/

4. Structure of sowing areas, predecessors, crop rotations (research and practice recommendations). Kyiv, 11 p., 2013.

5. Official announcer of Ukraine. 13, Art. 613, 2010.

6. Field, C.B., Barros, V.R., Dokken, D.J., Mach, K.J., Mastrandrea, M.D., Bilir, T.E., Chatterjee, M., Ebi, K.L., Estrada, Y.O., Genova, R.C., Girma, B., Kissel, E.S., Levy, A.N., MacCracken, S., Mastrandrea, P.R., and White, L.L. (eds.). Summary for policymakers. In: Climate Change 2014: Impacts, Adaptation, and Vulnerability. Part A: Global and Sectoral Aspects. Contribution of Working Group II to the Fifth Assessment Report of the Intergovernmental Panel on Climate Change. IPCC, Cambridge University Press, Cambridge, United Kingdom and New York, NY, USA, pp. 1-32, 2014.

7. AGRO-BUSINESS., About fertility of soil it is necessary to take care constantly. Available online: http://www.agrobusiness.com.ua/agronomiia-siogodni/694pro-rodiuchist-runtu-treba-dbatypostiino.html

8. Eurostat. Agriculture, forestry and fishery statistics. Statistical Book. Luxembourg, 2018.

9. State Statistics Service of Ukraine. Agriculture of Ukraine. Statistical Yearbook. Kyiv, 2018.

10.State Statistics Service of Ukraine. Environment of Ukraine. Statistical Yearbook. Kyiv, 2018.

11.Alcamo, J., Flörke, M., Märker, M. Future long-term changes in global water resources driven by socio-economic and climate changes. Hydrol. Sci. V.52, 247-275, 2007.

12.Ukraine: Soil fertility to strengthen climate resilience. Preliminary assessment of the potential benefits of conservation agriculture. FAO, Rome, p. 96, 2014.

13.To save the future: the first rating of innovative companies of Ukraine. Available online:

http://www.forbes.net.ua/magazine/forbes/1 416757-spasti-budushchee-pervyj-rejtinginnovacionnyh-kompanij-ukrainy

14.In an agrarian sector demand grew on "smart technologies". Available online: http://www.agroportal.ua/news/tekhnologii/ v-agrosektore-vyros-spros-na-umnyetekhnologii/

15. Organic in Ukraine. Available online: http://www.organic.com.ua/uk/homepage/2 010-01-26-13-42-29

16.LATIFUNDIST., Live Rating: Organic Agricultural Companies of Ukraine. Available online: https://www.latifundist.com/rating/toporgan ic\#197

17.Organic Agriculture in Ukraine: An Opportunity for Greening the Economy. Available online: http://www.greeneconomies-eap.org/ru/resources/Organicagriculture-Ukraine-UNEP-summary.pdf

18.VRU. Available online: http://w1.c1.rada.gov.ua/pls/zweb2/webpro c4_1?pf3511=60576.

19. Council Regulation (EC) № 834/2007 of 28 June 2007 on organic production and labeling of organic products and repealing Regulation (EEC) № 2092/91. Available online: http://www.eurlex.europa.eu/LexUriServ/LexUriServ.do?u ri= OJ:L:2007:189:0001:0023:EN:PDF

20.GOVERNMENT PORTAL., Association Agreement between the European Union and Ukraine. Available online: https://www.kmu.gov.ua/ua/diyalnist/yevro pejska-integraciya/ugoda-pro-asociacyu 